\title{
RESGATANDO A TRAJETÓRIA PROFISSIONAL DO ENFERMEIRO DO SEXO MASCULINO: UM ENFOQUE FENOMENOLÓGICO'1
}

\author{
THE MALE NURSE AND HIS TRAJECTORY: A PHENOMENOLOGICAL \\ RESEARCH \\ RESCATANDO LA TRAJECTORYA DEL ENFERMERO DE SEXO \\ MASCULINO: CON UN ENFOQUE FENOMENOLÓGICO
}

Carlos Eduardo dos Santos ${ }^{2}$ Regina Toshie Takahashi ${ }^{3}$

\begin{abstract}
RESUMO: Esta pesquisa teve como objetivo desvelar a trajetória de enfermeiros formados por uma escola pública. Para compreender essa vivência, optou-se por um estudo qualitativo, a partir da vertente fenomenológica segundo a modalidade "estrutura do fenômeno situado". Como forma de desvelar esse fenômeno, foram entrevistados doze enfermeiros, sendo que oito fizeram parte deste estudo. As proposiçőes que emergiram revelaram que a inserção no mercado de trabalho para o enfermeiro do sexo masculino é dificil; muitos hospitais particulares de São Paulo não admitem enfermeiros. Na atuação profissional, os enfermeiros têm bom relacionamento com os demais membros da equipe de Enfermagem e as equipes médicas valorizam o trabalho do enfermeiro quando este se mostra capaz e competente no desempenho de suas funçōes. As pacientes do sexo feminino aceitam serem cuidadas pelos enfermeiros do sexo masculino. No aspecto do relacionamento profissional com as enfermeiras do sexo feminino, existe discriminação por parte de algumas delas.
\end{abstract}

PALAVRAS- CHAVE : enfermeiro, mercado de trabalho, exercicio da enfermagem

\section{RECONHECENDO OPRÓPRIO PERCURSO}

Durante a graduação em Enfermagem, tive a oportunidade de compartilhar minhas inquietações, com alguns colegas que atuavam como auxiliares de Enfermagem e relatavam as dificuldades de como enfrentariamos o mercado de trabalho após a formação acadêmica.

A vida acadêmica transcorreu sem dificuldades tanto no relacionamento com os colegas e professores, ou no que se refere a aprovações nas disciplinas teóricas e nos estágios.

As dificuldades começaram quando iniciei a procura por emprego. Permaneci meses a procura de uma oportunidade de trabalho e as reflexões que afloravam a minha mente me inquietavam. Quais seriam as causas, por eu não estar empregado? Os fatores organizacionais estariam reduzindo o quadro de pessoal devido a crise econômica nacional? A cultura gerencial que exigia experiência anterior e como exigir experiência se não proporcionavam a oportunidade do primeiro emprego? Ou seria por ser homem em uma profissão predominantemente feminina? Surgiu a oportunidade de participar do processo seletivo de uma instituição hospitalar, consegui o emprego que buscava, sendo admitido como enfermeiro assistencial para prestar assistência

\footnotetext{
'Dissertação de Mestrado, apresentada na EEUSP na área de concentração de Administração do Serviço de Enfermagem - São Paulo -SP.

${ }^{2}$ Professor Ms. da disciplina Administração Aplicada à Enfermagem na Universidade do Grande $A B C$ e Universidade de Santo Amaro.

"Professora Dr." da EEUSP do Departamento ENO na disciplina de Administração .
} 
direta aos pacientes.

No transcurso dos anos, não encontrei obstáculos em prestar cuidados diretos ou na realização de exame físico às pacientes do sexo feminino que me aceitavam enquanto profissional. Também, não tive problemas em relacionar-me profissionalmente com a equipe multiprofissional.

Participando de eventos, conheci outros enfermeiros do sexo masculino e, muitas vezes, conversávamos, sobre o enfermeiro e a profissão Enfermagem, as dificuldades e facilidades. Nessas conversas informais, notei que muitas experiências se assemelhavam com as minhas, as dificuldades de inserção no mercado de trabalho e o cotidiano com as colegas enfermeiras eram as mesmas.

Após a conclusão da habilitação em saúde pública, e diversos eventos freqüentados, resolvi inscrever-me no processo de seleção do curso de Pós Graduação de uma Escola Pública na área de concentração de Administração de Serviços de Enfermagem.

Na pós-graduação, estimulado pela docente responsável pela disciplina e pelas colegas, iniciei um processo reflexivo mais contundente, repensei o meu vivencial na Enfermagem, contextualizando-o numa prática maior. Em uma dessas discussões, conversamos sobre as dificuldades que vivenciei na profissão e estimulado pelo grupo, resolvi estudar este tema.

Assim, para a realização da pesquisa, tento compreender como foi a trajetória dos enfermeiros do sexo masculino na profissão, diante das minhas inquietações.

Proponho como objetivo dessa pesquisa:

- Desvelar a trajetória dos enfermeiros do sexo masculino na profissão a partir da experiência destes sujeitos.

\section{RESGATANDO O CONHECIMENTO TEÓRICO}

Para uma maior compreensão do fenômeno estudado, faz-se necessário tecer considerações sobre a profissão Enfermagem.

Não há pretensão de se esgotar o tema, uma vez que o objetivo desta pesquisa é delimitar a compreensão do fenômeno "Trajetória dos enfermeiros do sexo masculino na Enfermagem", segundo a percepção de enfermeiros do sexo masculino.

É oportuno relembrar que a vivência de enfermeiros do sexo masculino na profissão Enfermagem não constitui uma regra, mas sim uma exceção que vem crescendo, ano após ano. Os indivíduos do sexo masculino sempre tiveram sua atenção voltada para profissões tradicionalmente masculinas de não evidenciar seus próprios sentimentos ou de outros, o que se revela na própria história do trabalho.

Desde os primórdios da história, na maioria das sociedades, os indivíduos do sexo masculino sempre foram os principais detentores de provimentos para o lar, o que vem mudando neste século. O trabalho sempre foi uma forma de afirmação do ser enquanto vivente em uma sociedade, quer seja nas primitivas ou nas modemas.

É através do trabalho que cada individuo se caracteriza em uma sociedade e é através desta caracterizaçăo que reproduz a sua própria existência, deixando, para a prosperidade, marcas indeléveis da sua passagem pelo planeta Terra.

A profissão Enfermagem foi influenciada pelas mudanças nas relações de trabalho ocasionadas pela revolução industrial.O termo mercado de trabalho consolida-se a partir da revolução industrial com novas formas de produção que necessitavam de modos mais dinâmicos de averiguação e controle da produção. "Com o nascimento das fábricas surge um primeiro paradigma da administração, defendendo racionalização da produção, divisão de tarefas em múltiplas etapas, a supervisão cerrada e a obediência hierárquica." (Ferreira, Reis, Pereira . 
1997, p.14)

Para compreensão do mercado de trabalho, este foi subdividido em áreas de atuação. Evidencia-se, neste estudo, o mercado de trabalho em saúde.

O mercado de trabalho em saúde aqui considerado será o mercado formal, institucional, regulamentado pelas associações de classe dos profissionais com graduação específica na área de atuação.

Vieira e Oliveira (1995, p.155) citam que existe uma considerável produção de estudos sobre mercado de trabalho em saúde, ora se fala da oferta de empregos e ora da oferta de profissionais. "Especificamente sobre o mercado de trabalho de Enfermagem, os estudos contemplam a oferta de empregos ou as necessidades de profissionais segundo as proporções com o número de habitantes, leitos e médicos." As autoras fazem a análise deste estudo, segundo a ótica da oferta e da demanda e concluem que "historicamente a geração de empregos não foi suficiente para garantir postos de trabalhos aos graduados em Enfermagem". Como conseqüência, é bastante precária a inserção dos enfermeiros no mercado de trabalho, existindo perda destes profissionais. Os setores públicos e privados fazem a manutenção da mão de obra não qualificada como suporte para a prestação de cuidados de Enfermagem.

A legislação, que subsidia a profissão Enfermagem, influencia a dinâmica do mercado de trabalho em saúde. Abordarei a legislação pertinente a esta categoria profissional, para esclarecer se existe algo que limite ou impeça a atuação do enfermeiro do sexo masculino.

No Brasil, muito se deve às entidades de classe da profissão que consolidaram a Enfermagem como uma profissão. A primeira destas entidades de classe foi a Associação Brasileira de Enfermagem, fundada em 1926 sob a denominação Associação Nacional de Enfermeiras Diplomadas, como uma sociedade civil com personalidade jurídica que congregava enfermeiros e técnicos de Enfermagem e que foi reconhecida como de utilidade pública sob o nome de Associação Brasileira de Enfermagem conforme Decreto Federal N. ${ }^{\circ} 31.417 / 52$ - DOU $11 / 09 / 52$.

Muitas lutas foram empreendidas pela classe até que se conquistou a LEI N. ${ }^{0} 2.604 / 55$, de 17 de Setembro de 1955 que regulamenta o exercicio de enfermagem profissional. Esta Lei foi um dos primeiros marcos da categoria; sua importância se deve à regulamentação do exercício profissional; dentre os artigos, podemos evidenciar alguns artigos referentes à atuação do enfermeiro. (Santos et al., 1997, p. 29).

Com a LEI N. ${ }^{\circ} 5.905 / 73$ são criados os órgãos disciplinadores para o exercício da profissão. O COFEN (Conselho Federal de Enfermagem) e os CORENs (Conselhos Regionais de Enfermagem) que constituiam em seu conjunto, uma autarquia vinculada ao Ministério do Trabalho e Previdência Social. Estes órgãos são disciplinadores do exercicio da profissão e das demais profissões compreendidas nos serviços de Enfermagem. Uma das funções do COFEN foi a elaboração do Código de Deontologia de Enfermagem e a instituição das cédulas de identidade profissional.

Vieira (1998, p.125) nos diz, “... atualmente esta entidade concentra grande poder decisório relativo ao exercício profissional da Enfermagem brasileira. O documento expedido pelos CORENs constitui a credencial reconhecida pelas instituições de saúde e de ensino no pais para a ocupação de postos de trabalho, documento indispensável em concursos ou processos de seleção para empregos ou cursos de pós-graduação lato sensu."

Em toda legislação profissional abordada, não há nada que possa impedir o livre acesso de homens enfermeiros à profissão.

Um outro fato importante são os levantamentos de recursos humanos, que as entidades de classe realizaram, pois, através destes, também pudemos ter um mapeamento da oferta e demanda de profissionais de Enfermagem e subsidios para a formação profissional, distribuição e utilização da força de trabalho no pais.

O primeiro estudo sobre levantamento de recursos e necessidades de Enfermagem foi 
realizado pela ABEn - Nacional no periodo de 1954/56 com assessoria técnica da Organização Mundial da Saúde e Instituto Brasileiro de Geografia e Estatística e financiado pela fundação Rockefeller.

Este estudo abrangia cinco áreas: "Enfermeiros em atividade e inativos, Enfermagem hospitalar, Enfermagem de Saúde Pública, Escolas de Enfermagem e Escolas de Auxiliar de Enfermagem. (...) Do relatório final, constou 46 recomendações dirigidas ao Ministério de Educação e Cultura, ao Ministério da Saúde, às universidades e legisladores, aos serviços de Enfermagem em unidades Sanitárias e hospitalares, à Conferência dos religiosos do Brasil, às instituiçöes que mantinham escolas de Enfermagem e de Auxiliar de Enfermagem e à ABEn. Esse relatório retratou a situaçăo da Enfermagem no Brasil até o ano de 1956, inclusive." (Carvalho, 1976, p.303)

O segundo estudo, desenvolvido em $1982 / 83$ pelo COFEN e $A B E n$, teve a finalidade de oferecer subsidios à necessária revisão do processo de formação, distribuição e utilização da força de trabalho em Enfermagem, de modo a promover sua adequação ao processo de desenvolvimento do pais.

Segundo pesquisa, (Moura et al., 1996, p. 9) do Conselho Regional de Enfermagem de São Paulo (COREN-SP) e Associação Brasileira de Enfermagem - Seção São Paulo (ABEnSP) intitulada "Força de trabalho em Enfermagem no Estado de São Paulo", teve como objetivos îdentificar a composição e a distribuição da atual força de trabalho em Enfermagem, identificar características das instituições de saúde e de ensino de Enfermagem, da força de trabalho em enfermagem e verificar as funções desempenhadas pelo pessoal de Enfermagem e a sua inserção nestas instituições no Estado de São Paulo.

Neste último estudo, estaremos evidenciando os dados referentes só à categoria de enfermeiros. Comparou-se, nesta pesquisa, os dados de 1983, sendo que naquela época haviam $8,3 \%$ de Enfermeiros do total de profissionais na Enfermagem e, em 1996, 11,0\%, havendo um aumento de $2,7 \%$ nesta categoria. Categoria enfermeiros do sexo masculino, havendo um aumento de $6,6 \%$ de 1983 para 1996 . Portanto, houve um aumento quantitativo de profissionais enfermeiros do sexo masculino, o que significa que existem mais homens procurando a profissão e que esta irá sofrer influências culturais e políticas e ocorrerão mudanças.

Vargens (1989, p.9), em seu estudo sobre a opção do profissional masculino pela Enfermagem, destacou que " (...) para o homem enfermeiro, a opção pela enfermagem não se dá de maneira estanque, mas sim, constitui um processo dinâmico, complexo, que se desenvolve ao longo de sua vida, e que envolve, além do processo de formação -processo formal - a construção da imagem enfermagem."

A partir dessa construção de imagem, o enfermeiro do sexo masculino conclui a graduação e caminha em busca da suas realizações profissionais construindo sua trajetória profissional.

\section{ESCOLHENDO O MÉTODO}

A pesquisa qualitativa foi a indicada para desvelar a trajetória dos enfermeiros na profissäo Enfermagem. Na perspectiva qualitativa, escolhemos a fenomenologia que é uma das formas de estudar esse fenômeno. A vertente fenomenológica utilizada foi a modalidade estrutura do fenômeno situado, segundo o referencial de Martins e Bicudo (1989).

\section{OBTENDO AS DESCRIÇÕES}

Em primeiro lugar, foi solicitado a uma Escola de Enfermagem pública a relação de nomes e endereços dos alunos do sexo masculino graduados desde a sua primeira turma até a de 1995 .

Para localização destes profissionais, enviei cartas, das quais obtive resposta de cinco. 
Para localizar os demais profissionais, fiz uma rede de informações junto aos que responderam as cartas, com a ajuda de colegas que atuam nas diversas instituições de ensino e assistência hospitalar da cidade de São Paulo. Localizei 16 profissionais.

Para realização das entrevistas, agendei com esses profissionais, local e hora por eles determinados. As entrevistas foram realizadas por mim com auxilio de um gravador, sempre com o consentimento e autorização do entrevistado, que estava ciente de que seu nome seria mantido sob sigilo e sob codificação do próprio autor. Após, estas entrevistas foram transcritas na sua integra para análise.

Foram entrevistados doze enfermeiros, sendo que após análise dos discursos oito foram realmente objeto de estudo, por terem desvelado a essência deste fenômeno.

Os discursos foram coletados com a seguinte questão norteadora " Discorra sobre a sua trajetória profissional".

Após a leitura dos discursos repetidas vezes, discriminei as unidades de significado, que são falas significativas para o pesquisador em relação à sua atitude e disposição, frente ao discurso dos entrevistados. Assim, realizei reflexões, com o propósito de chegar às categorias, tomando as unidades de significado e retirando delas a ingenuidade da descrição feita pelo sujeito.

Pela análise nomotética, que é a passagem do individual de cada discurso, para o geral, totalidade dos discursos, deu-se o agrupamento dos oito discursos com os temas respectivos.

Ao final do agrupamento das unidades de significado interpretadas, evidenciamos, em algarismos romanos, o discurso a que se refere, e em algarismos arábicos o número das unidades de significado, agrupadas no referido discurso.

\section{VIVENCIANDO O PROCESSO DE RECRUTAMENTO E SELEÇÄO}

1 - Após a formação acadêmica, recebeu uma proposta de trabalho do hospital que estagiava, passou pelo processo de seleção e foi aceito. Apesar de já ter um emprego foi fazer a inscrição para a seleção em um outro hospital de São Paulo. Foi impedido de fazer a prova, disseram que lá só se admitiam enfermeiras e se houvesse vagas para enfermeiro as provas seriam separadas. ( $1-1,2$ e 3 )

2 - Este profissional sentiu que a enfermeira do Serviço de Educação Continuada, tem uma postura diferente no processo de seleção em relação aos enfermeiros. (II - 1)

3 - Sentiu uma certa discriminação quando submeteu-se ao processo de recrutamento e seleção, pois algumas instituições hospitalares, não contratam enfermeiros, apenas pessoas do sexo masculino para o cargo de auxiliares de Enfermagem. (III-1, 3 e 4)

4 - Em alguns hospitais particulares de S.P. não se admitem enfermeiros. Chegaram a verbalizar que seria muito difícil conseguir emprego. Ficou um ano e meio desempregado, prestou concursos no serviço público por achar que teria maiores oportunidades. (IV $1,2,3,4$ e 5 )

5 - Considera seu primeiro emprego, como um dos únicos com perspectivas de ascensão profissional. Com 46 anos de idade, sendo homem, se precisar procurar emprego provavelmente terá muitas dificuldades. Existem hospitais em Săo Paulo com preconceito em admitir enfermeiros. $(V-1,3$ e 6$)$

6 - Existem hospitais que não admitem enfermeiros.( $\mathrm{VI}$ - 5)

7- Quando formou-se havia carência do profissional enfermeiro, e foi trabalhar em instituição pública, onde o serviço era valorizado, não tendo dificuldade em arrumar emprego. ( VII 1 e 2) 


\section{PARTICIPANDO DO PROCESSO DO CUIDAR}

8 - O enfermeiro não teve problemas em dar cuidados a pacientes do sexo feminino. Sente que o enfermeiro é valorizado pelas enfermeiras quando necessita realizar algum procedimento de Enfermagem com maior força muscular. As enfermeiras tentam sobressair-se na parte intelectual. ( 1 - 6, 7, 8 e 12)

9 - Quando se conquista o respeito do paciente, ele percebe o enfermeiro como profissional, independente do sexo. (II- 7)

10 - As pacientes aceitam e muitas vezes preferem ser cuidadas por enfermeiros. (III-5)

11 - Não houve problemas em cuidar de pacientes de ambos os sexos. Refere que devese agir com ética para superar os preconceitos e atender as necessidades do paciente, que te respeita independente de tua cor, sexo ou preferência sexual. (IV - 6, 7 e 10)

12 - Se a maioria dos profissionais está gerenciando e liderando as equipes, os enfermeiros também podem atuar na profissão, sem diferenças entre enfermeiros e enfermeiras. Os dois podem cuidar de ambos os sexos, porque se isto não for verdadeiro é considerado discriminação.( $\mathrm{VI}-6,7,8,9$ e 12)

13 - Quando estamos saudáveis o nosso preconceito é mais acentuado, do que quando estamos doentes, pois na doença queremos ser bem assistidos, independente de quem o faça. O enfermeiro nunca encontrou dificuldades em dispensar cuidados para pacientes do sexo feminino. (VII 3,4 e 5)

14 - Acredita que na assistência de Enfermagem não deva existir discriminação quanto ao sexo. ( VIII - 5)

\section{O RELACIONAMENTO INTERPESSOAL INFLUENCIANDO SUA TRAJETÓRIA}

15 - Sente que as enfermeiras a todo momento estão testando a capacidade , impedindo de conquistar espaço e mostrar seu valor. Algumas enfermeiras fazem barreira para o crescimento profissional. Na unidade de terapia intensiva teve menor dificuldade de aceitação. Os funcionários e médicos aceitam e respeitam sem dificuldades o trabalho do enfermeiro. $(1-4,5,6,9,10,11 \mathrm{e} 13)$

16 - Os médicos aceitam e respeitam o enfermeiro, o que não ocorre com as enfermeiras com mais tempo de formada, mas a medida que o tempo passa o relacionamento fica amistoso. Há um bom relacionamento com os funcionários. (II- 2, 3, 4, 5 e 6 )

17 - As enfermeiras com cargo superior, têm discriminação em relação ao enfermeiro quando este faz um trabalho que começa a ser reconhecido como bom pela equipe médica, elas o transferem de setor. Há um bom relacionamento do enfermeiro com os médicos. (III - 2, $6,7,8$ e 9 )

18 - Enfermeiras e auxiliares apreciam ter um enfermeiro no comando. Os médicos estranham no inicio, mas se consegue trabalhar bem com eles. (IV - 8 e 9 )

19 - Nos hospitais, existe um maior número de enfermeiras do que de enfermeiros. Enfermeiras não aceitam um enfermeiro na chefia. Os enfermeiros que não questionam são aceitos pelas diretoras de serviço, já os com conhecimento e que não toleram abusos, não são bem vistos. Não teve problemas de relacionamento com o pessoal de Enfermagem. (V - 2, 4, 5 , 7 e 8)

20 - A Enfermagem perde em termos de conquistas por ser predominantemente feminina. As enfermeiras brigam entre si, e muitos enfermeiros acabam tendo o mesmo comportamento, os que tentam fazer alguma coisa diferente são rejeitados. Não teve uma vivência problemática com as enfermeiras. ( $\mathrm{VI}-1,2,3$ e 4 )

21 - Apesar de alguns embates com os médicos, conseguiu sua independência e respeito quando mostrou-se competente como profissional. Com as colegas enfermeiras, sempre teve 
um bom relacionamento, apesar de algumas pensarem que a profissão é monopólio feminino e ficarem indignadas com essa presença masculina. Os enfermeiros estão na contra mão da história. Vivem numa sociedade machista, em uma profissão feminina, mas com o crescente aumento de enfermeiros na profissão, esta deverá sofrer transformações políticas e culturais e deve-se chegar a uma igualdade. A profissão deve perder o estigma de ser o auxiliar do médico e muitos não terão mais preconceito em falar que são enfermeiros. (VII 6, 7, 8, 9, 10, 11, 12, 13 , $14,15$ e 16$)$

22 - A sua experiência como docente em uma universidade foi boa, mas teve dificuldades em conviver com as colegas, que impediram o seu crescimento profissional. Refere que existe uma rejeição velada aos enfermeiros. As enfermeiras não abrem mão do seu espaço para nenhum enfermeiro. ( VIII-1, 2, 3 e 4)

\section{SINTESE}

O fenômeno desvelado nesta pesquisa, é a trajetória do enfermeiro do sexo masculino, com formação em uma escola pública, na profissão Enfermagem. Foi desocultado e compreendido o fenômeno

Os enfermeiros atuam em uma profissão histórica e culturalmente feminina. As chefias dos hospitais particulares de São Paulo, na sua grande maioria, são constituídas por enfermeiras que têm preconceitos em admitir enfermeiros. Este é um determinante de grande importância de dificuldade na inserção do enfermeiro do sexo masculino no mercado de trabalho.

No serviço público, não há preconceito para a admissão de enfermeiros do sexo masculino. Um profissional não conseguiu colocação em hospitais particulares e conseguiu iniciar sua trajetória pelo serviço público.

Em alguns hospitais particulares da cidade de São Paulo, que aceitam enfermeiros do sexo masculino, um profissional revela que, mesmo nestas instituições, existe no processo de seleção uma postura diferente em relação a eles.

Outro profissional questiona o porquê de não se admitir enfermeiros do sexo masculino em todas as instituições se o grande contingente da profissão está executando atividades de gerenciamento do cuidado e não está no cuidado propriamente dito.

Após conseguir colocação no mercado de trabalho, o enfermeiro se vê frente ao processo do cuidar. Este papel, cultural e historicamente de dar cuidados, não é aceito para homens, principalmente quando se fala em dispensar cuidados a pacientes do sexo feminino.

Não foi evidenciada, nesta pesquisa, a dificuldade em prestar cuidados de Enfermagem a pacientes do sexo feminino pela grande maioria dos entrevistados. Os depoimentos ressaltam que as pacientes do sexo feminino aceitam ser cuidadas por enfermeiros ou enfermeiras, quando há profissionalismo e ética e que é isto que elas priorizam na assistência e não o sexo do cuidador.Em uma das entrevistas, o enfermeiro revela que ele próprio tem bloqueios em dar cuidados a pacientes do sexo feminino.

Existem relações profissionais no cotidiano da vida do enfermeiro que influem sua trajetória, uma delas é com as equipes médicas que, no início, estranham a presença do enfermeiro, mas quando este se mostra capaz é aceito e há um bom relacionamento.

Na relação profissional com os demais membros da equipe de Enfermagem, também, aceita-se o enfermeiro e não há problemas de relacionamento entre eles.

Evidenciam-se também as relações com as colegas enfermeiras, onde há uma discriminação por parte delas, muitas vezes considerando o enfermeiro como um intruso e impedindo-os de conquistar espaço profissional; a todo momento, testam a sua capacidade e não aceitam um enfermeiro na chefia. Somente em uma fala, evidencia-se que as enfermeiras gostam de ser comandadas por um profissional do sexo masculino com a explicação que os homens têm história de comando e oferecem segurança e tranqüilidade à equipe. 
Alguns enfermeiros são aceitos, os que não questionam e são subservientes e os que têm o mesmo comportamento cultural das enfermeiras.

De acordo com o último levantamento de recursos humanos feito no Estado de São Paulo, o contingente de enfermeiros do sexo masculino está crescendo na profissão. Desvelouse que a profissão tende a sofrer modificações políticas e culturais, o que refletirá na somatória de valores dos indivíduos de ambos os sexos e a partir das diferenças, o crescimento da profissão e dos profissionais. Apesar dos homens estarem na contramão da história, ou seja, são homens em uma cultura machista, mas atuando em profissão de história feminina, têm muito a contribuir, o que foi apontado em um dos discursos como uma vantagem.

Como profissionais da área da saúde, devemos nos unir, enfermeiros e enfermeiras, para conseguirmos cada vez mais reconhecimento social e profissional para a categoria, tendo como principal objetivo prestar cada vez mais um melhor cuidado ao paciente.

As disputas profissionais por espaço de atuação devem advir da capacitação profissional de cada indivíduo e não do seu sexo, portanto os profissionais masculinos ou femininos devem capacitar-se cada vez mais, pois os mais preparados com os exercicios do pensar, sentir e agir, terão maiores condições de alterarem a sua prática,

Muitos são os acadêmicos de Enfermagem nos bancos escolares, por eles e por nós mesmos, devemos estar construindo constantemente uma profissão sem competições deletérias a ela; para tanto parafraseamos o tema do $47^{\circ} \mathrm{CBEn}$ "O poder (in) visivel da Enfermagem". Que todos os profissionais possam ter esta consciência.

ABSTRACT: The purpose of this article is to report on the trajectory of male nurses graduated from a public school. In order to understand this experience, a qualitative study was chosen, based on the phenomenological method, utilizing the concept of "situated phenomena structure". To reveal this phenomena, eight nurses were interviewed. The interviews showed that the insertion of male nurses in the labor market is difficult. Many private hospitals in São Paulo do not hire these nursing professionals. Professionally, male nurses have a good relationship with other members of the nursing team and doctors value their work when they perform competently. Female patients accept being cared by male nurses. Regarding the relationship with female nurses, it was observed that there is some discrimination on the part of them.

KEYWORDS: male nurse, labor market, nursing duty

RESUMEN:Esta investigación tuvo como objetivo desvelar la trayectoria de enfermeros diplomados por una escuela pública. Para comprender esa vivencia se optó por un estudio calitativo, a partir de la vertiente fenomenológica, según la modalidad "estructura del fenómeno situado". De doce enfermeros entrevistados, se escogieron ocho para formar parte del estudio. Las proposiciones recogidas revelaron que la incorporación al mercado de trabajo para el enfermero de sexo masculino es dificil; muchos hospitales particulares de São Paulo no los admiten. En la actuación profesional, los enfermeros tienen buen relacionamiento con los demás miembros del equipo de Enfermería y los equipos de médicos valorizan el trabajo del enfermero cuando este se muestra capaz y competente en el desempeño de sus funciones. Las pacientes de sexo femenino aceptan que los enfermeros de sexo masculino las cuiden. Respecto al relacionamiento profesional con las enfermeras de sexo femenino existe una discriminación por parte de algunas.

PALABRAS CLAVE: enfermeros, mercado de trabajo, ejercicio de enfermería 


\section{REFERÊNCIAS BIBLIOGRÁFICAS}

CARVALHO, A. C. de. Associação Brasileira de Enfermagem 1926-1976. Brasília: ABEn - Nacional, 1976. $514 p$.

FERREIRA, A. A.; REIS, A C. F; PEREIRA, M. I. Gestão empresarial: de Taylor aos nossos dias. São Paulo: Pioneira, 1997. $256 \mathrm{p}$.

MARTINS, J.; BICUDO, M. A V._A pesquisa qualitativa em fenomenologia: fundamentos e recursos básicos. Săo Paulo: Moraes/EDUC, 1989.

MOURA, M. L. P. de A et al. A força de trabalho em enfermagem no Estado de São Paulo. Sāo Paulo: COREN - Săo Paulo, 1996. 40p.

SANTOS, E. F., et al. Legislação em Enfermagem: atos normativos do exercício e do ensino de Enfermagem. Säo Paulo: Atheneu, 1997. 367p.

VARGENS, O.M. O homem enfermeiro e sua opção pela enfermagem. SãoPaulo,1989. 183p Dissertação (Mestrado) - Escola de Enfermagem, Universidade de São Paulo.

VIEIRA, A L. S.. Enfermeiros e o Mercosul: regulamentação e controle do exercicio profissional. Rev. Bras. Enferm., Brasilia, v.51, n.1, p. 123-138, 1998.

VIEIRA, A L. S.; OLIVEIRA, E. dos S. Mercado de trabalho da Enfermagem no Brasil: desvios da absorçăo dos profissionais. Rev. Enferm. UERJ, Rio de Janeiro, v.3, n.2, p. 155-165, 1995. 